\title{
A mensuração da satisfação dos clientes do setor público*
}

Revista do

Serviço

Público

Ano 51

Número 3

Jul-Set 2000

\author{
G. Ronald Gilbert \\ J.A.F. Nicholls \\ Sydney Roslow
}

\section{Introdução}

A finalidade deste estudo é identificar as características distintas dos usuários das agências governamentais e avaliar sua satisfação com os serviços prestados. Ao longo da última década, os serviços de qualidade e os serviços ao consumidor tornaram-se mandatos federais. O Presidente Bush incentivou o governo federal no sentido de demonstrar gestão de qualidade total em suas operações. O Presidente Clinton centrou-se na reinvenção do governo por meio de sua iniciativa chamada National Performance Review - NPR (Exame do Desempenho Nacional). O NPR prevê um setor público reduzido, voltado para os usuários, de trato fácil com os trabalhadores e administrado como as melhores empresas dos Estados Unidos. O Decreto Presidencial no 12.862 do Presidente Clinton, Setting Customer Service Standards 1993 (Estabelecimento das Normas do Serviço ao Usuário), desafiou as agências federais no sentido de melhorar os serviços prestados aos usuários. Especificamente, o decreto exige que as agências federais identifiquem seus usuários, façam levantamentos dos mesmos e determinem seu nível de satisfação com os serviços recebidos. A expectativa é de que o setor público normalmente alcance, ou exceda, o nível de satisfação verificado no setor privado (Schachter, 1997).

A fim de promover o bem comum, as agências públicas são orientadas por opções políticas e sociais que muitas vezes têm mais peso que as preferências pessoais de seus usuários. Conseqüentemente, o governo normalmente lida com pessoas e condições sociais que foram desconsideradas, esquecidas ou descartadas, assumindo assim desafios que não são enfrentados por empresas.

G. Ronald

Gilbert é

ex-professor do

Federal Executive

Institute $\mathrm{e}$

atualmente atua como professor associado de gestão e comércio internacional na Flórida International University.

J.A.F. Nicholls é professor de marketing, direção e ambiente empresarial na Flórida International University.

Sidney Roslow é professor emérito de marketing na Flórida

International

University.

Contato: tnovo@aol.com

Traduzido por Renê Loncan 28 
No mundo empresarial, os clientes insatisfeitos (e seu dinheiro)

normalmente vão procurar ser atendidos ou investir em outros lugares. No setor público, entretanto, os usuários satisfeitos com a prestação de serviços de bem-estar social podem ser considerados como um indicador negativo por aqueles cujas opiniões são vitais para o apoio ao funcionamento da agência. Assim, em vista da ausência das forças de mercado, os usuários insatisfeitos podem não ter a opção de ir procurar noutro lugar os serviços.

Quando o setor privado não pode atender a certas necessidades sociais, a sociedade depende de iniciativas do setor público. O Federal Reserve Board (Diretoria do Banco Central dos Estados Unidos), por exemplo, regula as instituições financeiras e, ao fazê-lo, ajuda a alimentar a máquina econômica do setor privado; os militares proporcionam a defesa para garantir a segurança com relação aos inimigos internos e externos. Incontestavelmente, o setor público é o último recurso em termos da garantia do bem-estar social, da regulação e de outras formas de proteção. Desde as linhas mestras da Constituição, nunca foi esperado que o governo provesse sistemas eficientes de prestação de serviços; em vez disso, sua função era prover um mecanismo para lidar com os interesses públicos díspares (Peters, 1991).

\section{Pedimos aos usuários do setor público que por favor se levantem}

Embora as empresas normalmente não tenham qualquer dificuldade em identificar seus clientes, as agências públicas têm problemas a este respeito (Hyde, 1991-1992; Linden, 1992-1993). Para o gerente e o funcionário do Wal-Mart, as pessoas que compram na loja são claramente seus clientes; para muitos prestadores de serviço no setor público, a definição de usuário é menos aguçadamente delineada. Por exemplo, quem são os usuários do professor da terceira série na escola pública oㅜ 12?

- Os alunos?

- Os pais?

- O Conselho de Educação?

Será que a satisfação dos alunos da terceira série corresponde à satisfação dos clientes na Macy's, na Borders ou na churrascaria do bairro? Será que o usuário do setor público tem sempre razão? Embora o agente do Internal Revenue Service - IRS (Serviço Interno da Receita dos Estados Unidos), possa ser um advogado de contribuintes, será função sua satisfazer a pessoa que está fraudando o público norte-americano? Como advogado do imigrante, estará errado o Immigration and Naturalization Service — INS (Serviço de Imigração e Naturalização), 
indeferir a petição de um candidato? Em resumo, será que atender às necessidades e às expectativas do usuário no setor público equivale ao que é feito no setor privado? A resposta pode ser sim em alguns casos, mas não em outros.

\section{A visão de Hyde dos usuários}

Hyde (1991-1992) apresentou um quadro geral para a definição do usuário do setor público. Ele sugeriu que as agências públicas têm consumidores como seus contrapartes do setor privado, embora também sirvam a outros usuários e a usuários cativos, que, segundo a definição de Hyde, não seriam clientes. Hyde limita seu primeiro tipo, os consumidores, a usuários que pagam por um serviço e também têm fontes alternativas se estiverem insatisfeitos com o serviço prestado pelo governo. Por exemplo, segundo Hyde, o serviço postal, os serviços de treinamento e os serviços de parques, todos esses servem a usuários. Seu segundo tipo, os usuários, provavelmente têm relações de prazo mais longo com seus prestadores de serviços, mas pouco controle sobre o que é cobrado, e são mais limitados em suas escolhas de provedores. Exemplos disso incluem clínicas de saúde ou escritórios de computadores. O terceiro tipo de usuário de serviços governamentais é o usuário cativo. Este tem poucas escolhas, se é que as tem, na seleção de seus fornecedores ou prestadores e tem menos capacidade de influenciar nos custos e na qualidade dos serviços prestados. Hyde identificou o Internal Revenue Service and Social Security Administration (Serviço Interno da Receita e Administração da Seguridade Social) como organizações que têm usuários cativos. Sem indicadores empíricos para apoiar sua proposta, Hyde sugere que a satisfação dos usuários é diferente entre consumidores, usuários e usuários cativos.

\section{A visão de Linden dos usuários}

Enquanto o foco de Hyde se aplica a pessoas que entram em contato direto com as agências públicas, Linden (1992-1993) sugere que as agências federais compreendem três espécies distintas de usuários. Essas espécies incluiriam clientes (aqueles que financiam a agência), consumidores (usuários finais semelhantes às três categorias de Hyde) e eleitores (pessoas e grupos com um interesse adquirido na finalidade da agência). Linden estimula o setor público a ser um agente do consumidor, como se espera que o seja um prestador de serviços do setor privado. Conseqüentemente, além de servir a seus consumidores, as agências públicas teriam de satisfazer a seus clientes e eleitores; ao contrário, o setor privado centra-se simplesmente nos consumidores que têm como meta para fins de lucro. 


\section{A avaliação da satisfação}

Para complementar o mandato do NPR do Presidente Clinton, este documento utiliza a classificação de Hyde dos tipos de beneficiários dos serviços federais, com uma diferença importante. Embora Hyde tenha denominado apenas um dos três tipos como consumidores e tenha excluído os outros, todos os três tipos estão incluídos como usuários do ponto de vista de uma agência. Conforme definido pelo Federal Benchmarking Consortium do National Performance Review (1997), usuário é "uma pessoa ou grupo que estabelece a necessidade de um processo e recebe ou usa os resultados dele; ou a pessoa ou entidade diretamente servida por um ministério ou agência." Conseqüentemente, demos novos rótulos aos usuários de Hyde, chamando-os de compradores diretos. É mais provável que as agências públicas sejam influenciadas pela voz de seus usuários quando esses são compradores diretos do que quando são usuários ou usuários cativos. Ao contrário, é menos provável que a voz deste preocupe os gerentes das agências do governo.

Independentemente de o consumidor ser um comprador direto, usuário ou usuário cativo, o mandato do Presidente Clinton incentiva as agências federais a medirem a satisfação de seus consumidores. Nós incluímos:

- a mensuração das diferenças em termos de satisfação com base no tipo de usuário servido pelas agências públicas; e

- as percepções sobre as diferenças entre usuários do governo.

A partir desses dados, aprenderemos, em primeiro lugar, se é factível medir a qualidade do serviço no governo por meio de instrumentos de mensuração de satisfação semelhantes aos do setor privado. Em segundo lugar, determinamos se a satisfação segue a previsão de Hyde, variando segundo o tipo de usuário a que as agências servem.

\section{Uma tríade de usuários do governo}

Esta seção identifica como os diferentes tipos de usuários do governo classificam a qualidade dos serviços recebidos, em seus papéis de compradores diretos, usuários e usuários cativos.

\section{Compradores diretos}

Os compradores diretos pagam pelos serviços que recebem. Eles têm grande influência nas atividades de seus fornecedores. As agências governamentais que os servem competem com prestadores de serviços dos setores privado e público. Como exemplos dessas agências federais, 
alinhamos a General Service Administration - GSA (Administração

de Serviços Gerais), que agora compete com o setor privado para a obtenção de contratos com agências federais — os centros de capacitação de pessoal da US Office of Personnel Management (Repartição para a Gestão de Pessoal dos Estados Unidos) e centros básicos de intercâmbio em complexos militares. Se os compradores não estiverem satisfeitos, terão a liberdade e a possibilidade de ir buscar serviços em outras fontes.

\section{Usuários}

Os usuários têm uma escolha limitada para selecionar seus prestadores de serviços. Eles têm menos influência que os compradores diretos sobre as operações, a qualidade de serviço e os preços de seus fornecedores. Um comprador direto pode escolher um prestador de serviços médicos entre todos os médicos que figurem nas páginas amarelas. No entanto, aqueles que forem cobertos apenas por apólices do Department of Veterans Affairs - VA (Departamento de Assuntos dos Veteranos), são usuários, porque suas escolhas estão restritas aos serviços inseridos naquela estrutura. Outros exemplos de usuários incluem passageiros de baixa renda no sistema público de transportes, ou cidadãos que necessitem de licenças para construção. Em cada um desses casos, os usuários não têm a liberdade de escolher entre agências que concorram num sistema de mercado. Suas escolhas são limitadas, centrando-se em usar ou não usar o serviço. Embora a satisfação dos usuários seja importante para seus fornecedores, essas agências provavelmente se concentram mais nas expectativas de seus eleitores (conforme Linden) do que aquelas que servem a compradores diretos.

\section{Usuários cativos}

Os usuários cativos têm oportunidades muito limitadas de escolha. Isso porque as agências que os servem normalmente estão cumprindo um mandato político. Particularmente, essas agências reagem às necessidades de seus eleitores, isto é, aqueles com um interesse adquirido na agência. Como resultado, os sistemas que servem a esses usuários são mais provavelmente influenciados por seus eleitores que as agências que servem aos compradores diretos ou usuários. Se um eleitor for influente, um usuário cativo poderá perfeitamente ficar frustrado, isto é, ter um nível mais baixo de satisfação. Como exemplos de agências federais que servem a usuários cativos incluem-se o INS, a Federal Corrections Agency e a Social Security Administration (Administração da Seguridade Social). Afora os direitos deste tipo de usuário como cidadãos, eles têm menos voz ativa na condução dos negócios das agências que os compradores diretos ou os outros usuários. 


\section{As chaves da satisfação dos usuários}

Durante o período de 1993 a 1997, realizou-se uma pesquisa para criar um levantamento padronizado de satisfação de usuários, aplicável tanto ao setor público quanto ao privado (Gilbert, 1996). Para as agências governamentais, o levantamento foi realizado junto a usuários quando terminavam seu contato com a prestação de serviços. $O$ instrumento do levantamento consistia de indicadores válidos e confiáveis para avaliar a satisfação dos usuários nos dois setores (Nicholls, Gilbert e Roslow, 1998). Os dados foram analisados para determinar se havia diferenças significativas na satisfação deles. A partir dessa pesquisa interativa, identificaram-se dois indicadores genéricos de satisfação com os serviços: a satisfação com o atendimento pessoal recebido e a satisfação com o ambiente no qual o serviço era prestado. Explicaremos a seguir esses tipos de satisfação.

\section{Satisfação com o atendimento pessoal}

A maneira pela qual um prestador de serviço trata um usuário é a base da satisfação do mesmo. Esse aspecto da satisfação é muitas vezes uma função do serviço face a face. Poderia ser demonstrado por um recepcionista, seja numa agência penitenciária federal, seja no consultório de um médico particular, que saúda o visitante com um sorriso, estabelece contato visual positivo e responde às perguntas dele com competência.

\section{Satisfação com o ambiente do serviço}

Por mais satisfeito que um usuário possa estar com o elemento pessoal do serviço, essa satisfação pode ser diminuída pelo ambiente no qual o serviço é prestado. Por exemplo, se a mesma agência penitenciária federal ou o mesmo consultório médico estiverem desarrumados, se a sala da recepcionista estiver cheia de gente, se o vendedor se sentir inseguro, ou se as horas de expediente não forem convenientes, a satisfação dos usuários será afetada. Em suma, esses elementos são uma função do ambiente do serviço, em oposição aos contatos pessoais diretos entre prestador e consumidor.

\section{Metodologia}

Os contatos diretos dos usuários com agências governamentais foram avaliados usando-se o levantamento de satisfação dos usuários. O instrumento é uma escala reduzida, que compreende cinco afirmações que possibilitam medir a satisfação com o serviço pessoal, como por 
exemplo: a competência dos funcionários, o tratamento recebido, a cortesia do prestador, a facilidade em ser atendido e o serviço prestado a tempo. Quatro outras afirmações servem para classificar a satisfação dos usuários com o ambiente do serviço: a segurança fora da organização, a limpeza, a segurança dentro da organização e o horário de expediente conveniente. Os entrevistados indicaram seu grau de satisfação utilizando uma escala de cinco pontos, indo do item 1, "discordo fortemente" ao 5, "concordo fortemente". Assim, os dois indicadores de satisfação para um entrevistado eram a média das afirmações que classificavam o serviço pessoal e o ambiente do serviço.

Os usuários foram colocados em amostragem a partir de 13 diferentes agências federais, estaduais e regionais/locais (Tabela 1). Essas agências cobriam uma vasta gama de serviços governamentais, inclusive segurança pública, transporte de superfície e aéreo, bibliotecas públicas e serviços de alimentação. Os dados foram obtidos aplicando-se o levantamento de satisfação a 2.978 usuários que utilizavam esses serviços. Esses usuários foram então classificados quanto a seu grau de liberdade para escolher o serviço governamental, ou seja, como compradores diretos, usuários e usuários cativos.

\section{Três tipos de usuários do governo}

\section{Compradores diretos}

Os que freqüentaram o US OPM's Western Management Development Center (Centro de Treinamento Gerencial do Oeste do US OPM) foram considerados aqueles que tinham alto nível de escolha, uma vez que os compradores diretos podem selecionar seus fornecedores. A maior fonte de financiamento da agência é a renda gerada a partir desses consumidores. Os consumidores insatisfeitos podem não voltar para receber treinamento adicional e impedir qualquer outra pessoa de suas agências de freqüentar o centro. Conseqüentemente, a aprovação do comprador direto é fundamental para o estabelecimento dos programas de treinamento, para a identificação dos apresentadores e para outros componentes essenciais do sistema de prestação. As porpostas impopulares são abandonadas e substituídas por tópicos que interessem aos compradores diretos da agência.

\section{Usuários}

Aqueles que buscaram os serviços das clínicas de veteranos, das agências dos serviços postais, de repartições locais de licenças para 
construção, de serviços de transporte de massa, de bibliotecas de universidade, de bibliotecas locais e de lanchonetes nos campus das universidades foram classificados como usuários. Em cada uma dessas organizações, os usuários foram percebidos por terem alguma possibilidade na escolha do serviço ou por influírem na formulação de políticas da agência.

\section{Usuários cativos}

Esta categoria incluiu os usuários do INS, das repartições da Seguridade Social, de uma operação de segurança pública numa universidade, de um departamento de veículos automotores e de um aeroporto internacional. Os serviços prestados por essas agências governamentais são virtualmente independentes da influência dos usuários cativos.

Tabela 1: Tamanho da amostra do setor público em compradores diretos, usuários e usuários cativos

\begin{tabular}{|c|c|c|c|c|}
\hline Agência & $\begin{array}{l}\text { Compradores } \\
\text { diretos }\end{array}$ & Usuários & $\begin{array}{l}\text { Usuários } \\
\text { cativos }\end{array}$ & $\begin{array}{l}\text { Tamanho da } \\
\text { amostragem }\end{array}$ \\
\hline \multicolumn{5}{|l|}{ Governo Local/Regional } \\
\hline $\begin{array}{l}\text { Repartições de licenças para } \\
\text { construção }\end{array}$ & & 205 & & 205 \\
\hline Biblioteca pública & & 174 & & 174 \\
\hline Transporte de massa & & 674 & & 674 \\
\hline Aeroporto internacional & & & 159 & 159 \\
\hline \multicolumn{5}{|l|}{ Governo Estadual } \\
\hline Lanchonete da universidade & & 376 & & 376 \\
\hline $\begin{array}{l}\text { Segurança pública na } \\
\text { universidade }\end{array}$ & & & 200 & 200 \\
\hline Biblioteca da universidade & & 196 & & 196 \\
\hline $\begin{array}{l}\text { Departamento de veículos } \\
\text { automotores }\end{array}$ & & & 148 & 148 \\
\hline \multicolumn{5}{|l|}{ Governo Federal } \\
\hline $\begin{array}{l}\text { Serviço de Imigração e } \\
\text { Naturalização }\end{array}$ & & & 351 & 351 \\
\hline Seguridade Social & & & 208 & 208 \\
\hline Serviços postais & & 100 & & 100 \\
\hline $\begin{array}{l}\text { Serviço de Capacitação } \\
\text { Gerencial do Oeste }\end{array}$ & 74 & & & 74 \\
\hline Clínica de Veteranos & & 113 & & 113 \\
\hline Total & 74 & 1.838 & 1.066 & 2.978 \\
\hline
\end{tabular}


As respostas dos compradores diretos, dos usuários e dos usuários cativos no âmbito do setor público foram comparadas e são apresentadas no Gráfico 1.

\section{Gráfico 1: Nível de satisfação dos compradores diretos, dos usuários e dos usuários cativos}
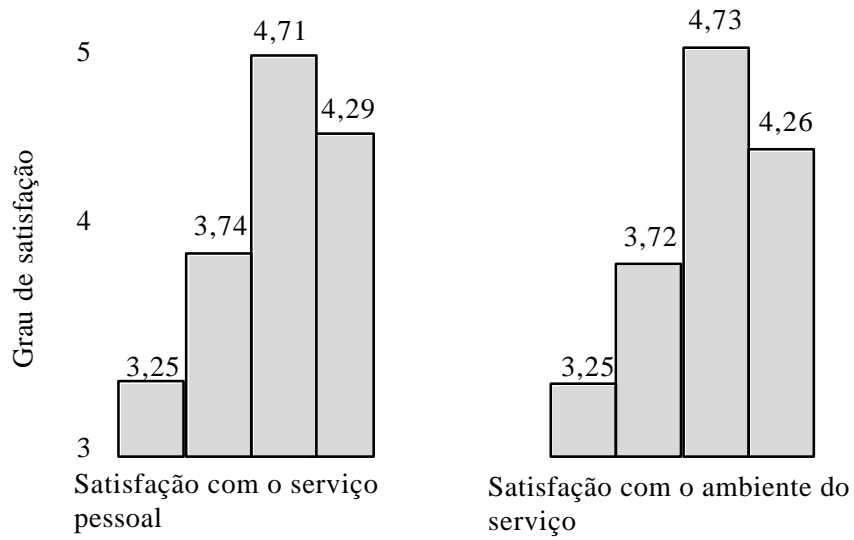

Baseado numa escala de cinco pontos, de 1 "discordo fortemente" a 5 "concordo fortemente"

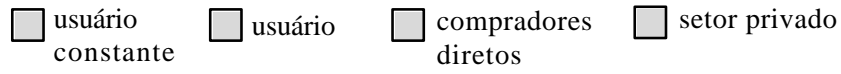

Os dados apóiam a premissa de Hyde (1992). A organização governamental que lida com compradores diretos (Hyde chamou-os consumidores) gozou de níveis significativamente mais altos de satisfação que aquelas que atendem a usuários ou a usuários cativos. As agências que servem a estes receberam classificações mais baixas, o que sugere que eles estavam indecisos quanto a sua satisfação com os serviços. Quando comparados com amostragens de 4.234 e 3.991 do setor privado, os compradores diretos do setor público classificaram sua satisfação com o serviço pessoal, $x=4,71$, e a satisfação com o ambiente do serviço, $x=4,73$, bem mais altas que no setor privado, $x=4,29$ e $x=4,26$, respectivamente. Os resultados indicam que, quando a aprovação dos usuários conduz uma agência do governo, é mais provável que o sistema seja reativo a eles que quando os seus desejos correspondem a uma preocupação secundária.

A diferença nas classificações segundo os tipos de usuários sugere que aqueles que têm liberdade de escolha — os compradores diretos - estavam muito satisfeitos com seus fornecedores; com efeito, suas necessidades estavam atendidas. Na extremidade inferior, aqueles com menor possibilidade de escolha estavam menos satisfeitos. Sua insatisfação 
pode ser um reflexo das opções limitadas; alternativamente, sua relativa

insatisfação pode ser atribuível às atitudes e ao comportamento do pessoal das agências.

\section{Conclusão}

O estudo demonstra que, quando os usuários têm influência dentro de uma agência pública, seu nível de satisfação é mais alto. No entanto, quando os usuários têm pouca ou nenhuma influência, o desempenho das agências governamentais recebe classificação mais baixa.

Em nosso delineamento, o perfil sugere que a qualidade do serviço prestado a usuários de agências pode ser medida e pode afinar a maneira pela qual as agências são gerenciadas, melhorando o uso de seus recursos para prestar tais serviços.

Nossas conclusões sugerem fortemente que, quando os compradores diretos estão envolvidos, as agências do governo demonstram excelente atenção com eles - equivalente ao que se encontra no setor privado. No entanto, quando a agência federal é concebida para lidar com usuários ou usuários cativos, pode ser desejável mudar o padrão de mensuração. Nesse caso, é preferível que sejam desenvolvidos indicadores mais adequados à determinação de como os usuários são tratados. Embora a satisfação dos usuários seja um indicador vital para sistemas orientados pelo mercado, em organizações que servem ao bem maior, sua satisfação final pode não ser um indicador tão apropriado. A qualidade dos serviços prestados em termos de assegurar os direitos pessoais, a segurança e a saúde pode ser um indicador mais relevante.

Por exemplo, a satisfação de um prisioneiro no sistema carcerário pode não ser um indicador tão válido da eficácia geral de uma prisão se comparado com a satisfação de um usuário dos serviços do GSA. O que pode ser importante é se os prisioneiros estão efetivamente detidos enquanto simultaneamente seus direitos são assegurados. $\mathrm{O}$ desempenho satisfatório, desse ponto de vista, pode ser muito diferente do que se conclui quando se faz um levantamento da satisfação dos presos.

Os indicadores de satisfação de usuários parecem ser termos de comparação apropriados para agências governamentais que atendem a compradores diretos que gozam de liberdade de escolha. Com efeito, nosso estudo sugere que, quando o campo de ação é equivalente, o setor público pode atingir, ou ultrapassar, as taxas de satisfação desses usuários alcançadas pela empresa privada. Para agências governamentais que atendem a usuários e usuários cativos, que não têm uma liberdade de escolha concomitante, esses indicadores podem distorcer o entendimento do real desempenho dessas agências. Recomendamos indicadores alternativos, oportunos e independentes da satisfação dos usuários para medir o desempenho de agências que atendem a usuários e a usuários cativos. 
* Este estudo foi publicado originalmente em inglês, sob o título Measuring public sector customer service satisfaction na revista The Public Manager (vol. 27, n.4, winter 1998-1999).

\section{Referências bibliográficas}

Clinton, Bill; Gore, Al. (1995), "Putting customers first: standards for serving the American people”. National Performance Review. Washington D.C: US Government Printing Office.

Federal Benchmarking Consortium Study Report. (1997), Serving the American public: best practices in customer-driven strategic planning. Washington D.C: US Government Printing Office.

Gilbert, G.R. (1996), Customer satisfaction survey. Boca Raton F.L.: Management Education and Development Inc.

Gore, Al. (1997), "Businesslike Government: lessons learned from America's best companies". National Performance Review.

Hyde, Albert C. (1991/2), "Feedback from customers, clients and captives". The Bureaucrat, 20 (4), p. 49-53.

Linden, Russell. (1992/2), "Meeting which customers?" The Public Manager, 21(4), p. 49-52.

Nicholl, J.A. F., Gilbert, G.R., Roslow, Sydney. (1998), "Parsimonious measurement of customer satisfaction with personal service and the service setting." Journal of Consumer Marketing, 15 (3), p. 239-253.

Peters, Tom. (1991), "Excellence in Government? I'm all for it! Maybe." The Bureaucrat, 20 (1), p.3-6.

President Executive Order. (1993), "Setting customer service standards". Executive Order 12862. Washington D.C.

SCHACHTER, Hindy L. (1997), Reinventing Government or reinventing ourselves: the role of citizen owners in making a better Government. Albany: State University of New York Press. 


\section{A mensuração da satisfação dos clientes do setor público}

G. Ronald Gilbert, J.A.F. Nicholls e Sydney Roslow

Ano 51

Número 3

Jul-Set 2000

Este estudo demonstra que, quando os usuários têm influência dentro de uma agência pública, seu nível de satisfação é mais alto. No entanto, quando os usuários têm pouca ou nenhuma influência, o desempenho das agências governamentais recebe classificação mais baixa. $\mathrm{O}$ estudo pretende identificar as características distintas dos usuários das agências governamentais e avaliar sua satisfação com os serviços prestados.

\section{La mensuración de la satisfacción de los usuarios del sector público}

\section{G. Ronald Gilbert; J. A F Nicholls y Sidney Roslow}

Este estudio demostra que cuándo los usuarios tienen influencia dentro de una agencia pública, su nivel de satisfacción es más alto. Sin embargo, cuándo los usuarios tienen poca o ninguna influencia el desempeño de las agencias gubernamentales recibe clasificación más baja. El estudio pretende identificar las características distintas de los usuarios de las agencias gubernamentales y evaluar su satisfacción com los servicios prestados.

\section{Measuring public sector customer service satisfaction}

\section{G. Ronald Gilbert; J. A F. Nicholls and Sidney Roslow}

This study demonstrates that where users are influential within a public agency, their level of satisfaction is higher. However, where users had little or no influence, government agencies performance was rated lower. This study intends to identify the distinctive characteristics of government agencies "customers" and assess their satisfaction with the services rended.

G. Ronald

Gilbert é ex-professor do Federal Executive Institute e atualmente atua como professor associado de gestão e comércio internacional na Flórida International University.

J.A.F. Nicholls é professor de marketing, direção e ambiente empresarial na Flórida International University.

Sidney Roslow é professor emérito de marketing na Flórida International University. 